\title{
AC 2007-1205: TRAVELING ENGINEERING ACTIVITY KITS - ENERGY AND THE ENVIRONMENT: DESIGNED BY COLLEGE STUDENTS FOR MIDDLE SCHOOL STUDENTS
}

\section{Elizabeth DeBartolo, Rochester Institute of Technology}

ELIZABETH A. DEBARTOLO is an Associate Professor in the Mechanical Engineering Department at the Rochester Institute of Technology. She earned her BSE at Duke University in 1994 and her MSME and Ph.D. at Purdue University in 1996 and 2000, respectively. She works with several students in the area of fatigue life prediction. Dr. DeBartolo serves on her college's leadership teams for both multi-disciplinary capstone design and outreach program development.

\section{Margaret Bailey, Rochester Institute of Technology}

MARGARET BAILEY, registered professional engineer, is the Kate Gleason Chair and Associate Professor in Mechanical Engineering at RIT. She earned her BSE at Pennsylvania State University in 1988 and her Ph.D. at University of Colorado at Boulder in 1998. She conducts research with students using advanced thermodynamic analyses and neural network modeling applied to various, energy-intensive, complex mechanical systems. Dr. Bailey serves in numerous leadership roles within her college, including Executive Director of RIT's Women in Engineering Program (WE@RIT); ME Department Advocate for Engineering Honors Program; and Member of Multidisciplinary Capstone Design Leadership Team.

\section{Melissa Zaczek, Cummins}

MELISSA ZACZEK is a Performance Development Engineer with Cummins Emission Solutions. She earned her Bachelors of Science and Masters of Engineering in Mechanical Engineering from Rochester Institute of Technology in 2006. She served as Project Manager of the TEAK Team and also has presented the kits at multiple conferences.

Timothy Schriefer, Rochester Institute of Technology

TIMOTHY SCHRIEFER is a 2007 graduate of RIT with a dual BS/MS in Mechanical Engineering and was a member of the TEAK senior design team. His thesis research was in the area of thermoelectrics and alternative fuels.

\section{Patrick Kelley, Carnegie Mellon University}

PATRICK GAGE KELLEY is a PhD Student at Carnegie Mellon University in Computation, Organization \& Society. He earned two BS degrees in Computer Engineering and English Literature from the Rochester Insitute of Technology in 2006. Currently he works in information visualization and case-based explanation techniques surrounding user's privacy policies.

\section{Mallika Ramaswamy, Rochester Institute of Technology}

MALLIKA RAMASWAMY is in the Operations Management Leadership Development Program with General Electric's Energy division. She earned her Bachelor of Science in Industrial Engineering and Master of Engineering in Engineering Management from the Rochester Institute of Technology in 2007. She was a member of the team that designed the TEAK kits and served as an educator in outreach development activities incorporating the TEAK kits. Her research interests are in the area of sustainability, energy and policy.

\section{Nicholas Ryczko, Pratt \& Whitney}

NICHOLAS RYCZKO is an Aero/Thermo Engineer in the Advanced Engines Performance group at Pratt \& Whitney. He earned his Bachelor of Science in Mechanical Engineering from the Rochester Institute of Technology in 2006. He was a member of the team that designed the TEAK kits and served as an educator in outreach development activities incorporating the TEAK 
kits in 2006. His research interests are in thermodynamics and supersonic aerodynamics.

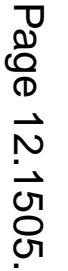




\title{
Traveling Engineering Activity Kits - Energy and the Environment: Designed by College Students for Middle School Students
}

\begin{abstract}
A 2005-06 Multidisciplinary Senior Design team created a series of classroom activities designed to teach middle school students about engineering topics related to energy and the environment. This traveling engineering activity kit (TEAK) project consists of five kits, each based on a different energy-related theme: Heat Transfer, Electrical Energy, Wind and Water, Solar Power, and Chemical Energy. Each kit contains an Academic Activity to teach a background concept, a Hands-On Activity to allow students to apply the concepts learned, and a Take-Home Activity that can be done independently at home. The design team also developed instruction manuals suitable for non-engineers, lesson plans, handouts, and post-activity quizzes to assess participants' learning. To date, the kits have been used by over $1006^{\text {th }}$ graders as well as dozens more students participating in on-and off-campus outreach programs. This paper describes how and why undergraduate engineering students were involved in designing the TEAK educational tool, including a detailed list of customer needs and design specifications that were defined during their design process. Discussions are also included on the basic TEAK structure, kit descriptions, and assessment results to date.
\end{abstract}

\section{Introduction}

As the number of retirements in science and engineering and the demand for trained professionals in those fields increases, while enrollment in college degree programs in those fields remains steady, our nation may be facing a shortage of scientists and engineers ${ }^{1}$. It is important to increase general interest in engineering, and one way to do this is to encourage precollege students from traditionally underrepresented groups to enter into engineering careers. For example, women make up approximately $50 \%$ of the population, yet only represent about $20 \%$ of college-aged engineering students ${ }^{2}$. Women are, however, represented in higher numbers in fields such as Environmental, Biomedical, and Chemical Engineering ${ }^{3}$. Since these fields seem to hold special appeal for women, it was a natural decision to choose one of them as a topical focus for the present project.

A unique aspect of the Traveling Engineering Activity Kit (TEAK) project was the decision to involve undergraduate students in the design of the activities and accompanying materials, as well as the presentation of the activities to middle school students. Prior studies support this decision, indicating that middle school teachers tend to feel strongly about the importance of design, engineering, and technology, but do not have familiarity with the material ${ }^{4}$. During the 2005-06 academic year, a team of Multidisciplinary Senior Design (MSD) students set out to design, build, and test a series of hands-on activities intended to increase awareness of and interest in engineering as a field of study. These activities all centered on a theme of how engineering work can be related to energy and the environment. During the 2006-07 academic year, a second team of Software Engineering students is working to design an interactive companion website to the TEAK activities. 
The objectives of the TEAK project are as follows:

1. Encourage middle school students to consider engineering as a career choice

2. Teach students basic engineering concepts related to energy and the environment

3. Introduce middle school students to the scientific method as well as the engineering design process

4. Create a mechanism to bring engineering activities into local K-12 classrooms

The kits were tested on approximately 100 students during 2005-06, and during the 2006-07 academic year the kits are being regularly used by $5^{\text {th }}-8^{\text {th }}$ grade teachers in their classrooms. The 2006-07 testing includes teachers who are doing the instruction themselves and teachers who are bringing RIT students in to do the instruction. Within the following sections of this paper, we will first describe how and why undergraduate engineering students were involved in designing the TEAK educational tool, including a detailed list of customer needs and design specifications that were defined during their design process. Discussions are also included on the basic TEAK structure, kit descriptions, and assessment results to date.

\section{Engineering Students Designing Educational Tools}

Each of the TEAK kits was developed by a team of students from Computer, Electrical, Mechanical, and Industrial Engineering, as well as one Industrial Design student. While the theme of the kits was required to center on energy and the environment, one of the goals of the kits was to be able to use the activities to teach pre-college students about the variety of career opportunities available in engineering related to the kit theme. By assembling a multidisciplinary team, it was possible to highlight the contributions of different disciplines to the energy/environment theme. In the existing kit, the team focused on Mechanical, Chemical, and Electrical Engineering concepts.

\begin{tabular}{|l|l|}
\hline Educates About Energy And The Environment & Portable \\
Should support NYS curriculum & Lightweight \\
Completed in a reasonable time period & Easy to move \\
Concepts relate to a larger system & Fits Into average car trunk \\
Things students can see or do at home & Durable \\
Not intimidating to presenters & Easily assembled/disassembled \\
Discusses the role of engineering In society & Waterproof container \\
& Prevents spills \\
& Ergonomic design \\
\hline Interactive & Safe \\
Involves all levels of Bloom's Taxonomy & No hazardous materials \\
Is enjoyable for middle school students & Does not require hazardous waste clean-up \\
Allows experimentation & Operable by middle-school students \\
& Clear step-by-step directions \\
& No sharp corners \\
& Low voltage \\
& Ability to stop mid operation \\
& Wires insulated properly \\
& Operation and safety sticker \\
\hline
\end{tabular}

Table 1. Customer needs, according to category. 
Since the kits were developed as part of a two-quarter MSD course, the team followed a traditional design process. Prior to the start of group work, the team's project manager met with the customers, two faculty members in Mechanical Engineering (and co-authors on this paper), to identify and prioritize customer needs. Based on this preliminary information and observations from benchmarking against a similar kit used by $\mathrm{ASHRAE}^{5}$ and some museum exhibits, the team completed a QFD analysis, relating customer needs (Table 1) to measurable design specifications (Table 2) and brainstormed ideas for kits and activities. The team developed ideas for a single prototype kit, performed the analysis required to ensure the activities would work, built the kit, and tested it with small groups of students. Based on feedback and observations from this prototyping, the team adjusted their plans for developing the remaining kits. By the end of the first quarter, the team had ideas for five different energy-themed kits and an outline for the structure of each kit.

During the second quarter of MSD, the team refined the initial kit, designed and built the remaining four kits, and tested the kits extensively with groups of middle school students. Within the two course sequence, the Mechanical, Electrical and Computer engineers contributed primarily to the design and analysis required to develop the different activities. The Industrial and Systems Engineering students handled documentation (with the Computer Engineering student) and assessment issues, and the Industrial Design student worked with the engineers on construction of the actual devices.

\begin{tabular}{|l|c|}
\hline Engineering Metrics & Specifications \\
\hline Weight & $<50$ lbs per kit \\
\hline Dimensions & $15.8 \mathrm{ft}^{3}$ \\
\hline Parts (\#) & $<100$ per kit \\
\hline Assessment tests & Demonstrate improvement \\
\hline Hand-on time & 2 minutes \\
\hline Average length per kit & $\geq 1$ Meets evaluation level \\
\hline Blooms Taxonomy test & $<30$ \\
\hline Steps to assemble (\#) & $<30$ \\
\hline Steps to disassemble (\#) & 15 minutes \\
\hline Time to assemble & 5 minutes \\
\hline Time to disassemble & 0 \\
\hline Tools required (\#) & 0 \\
\hline Flammability rating & 0 \\
\hline Toxicity rating & 0 \\
\hline Explosive material rating & 0 \\
\hline Fragile parts (\#) & Y \\
\hline Voltage & 150 degrees \\
\hline Emergency shut down (y/n) & 200 lbs \\
\hline Temperature limit & $\geq 2$ \\
\hline Force able to withstand & 50 \\
\hline Handles (\#) & $\geq 1$ per kit \\
\hline$\#$ of times it can be dropped & 1 hour \\
\hline Take home activities (\#) & 10 years \\
\hline Time to prepare & \\
\hline Life expectancy & volts or standard outlet \\
\hline Table 2. Design specifcations & \\
\hline
\end{tabular}

Table 2. Design specifications 
As a follow-on project, a senior design team from Software Engineering is developing an interactive companion website for the TEAK kits during the 2006-07 academic year. This model is similar to the TIES program ${ }^{6}$, only the in-class and computer-based activities with TEAK are all designed and created by engineering students. The website will be set in "TEAKTown", an environmentally-conscious town complete with a school for visitors to ask questions, a library for visitors to look up information, and an arcade for visitors to play energy-related online games. Since the focus of the Software Engineering students will be on the programming and functionality of the site, they have partnered with a Mechanical Engineering class (Contemporary Issues in Energy and the Environment) to develop the site's content; the ME class will also provide any modeling required for the game background. The website is expected to be ready for preliminary testing by late February 2007 and fully functional by May 2007 .

\section{TEAK Structure}

Each TEAK kit covers a different energy-related theme, and contains an instruction manual, an academic activity, a main activity, and a take-home activity; details for each are included below. Within a set of activities, the middle school students should be exposed to educational activities ranging from basic comprehension to design and evaluation to reflecting on what they've learned at home. The design team used Bloom's Taxonomy ${ }^{7}$ as a guideline in this, and similar goals have been set for other middle school engineering modules ${ }^{8}$. Kits developed to date include Heat Transfer, Chemical Energy, Electrical Energy, Solar Power, and Wind and Water Power.

Instruction Manual: The instruction manual consists of a guide sheet, lesson plans, handouts, and assessment forms. The contents of the Instruction Manuals are available online so teachers can browse and decide which kit(s) to use or prepare ahead of time for the kits that they have already reserved.

- Guide Sheet - An overview of the kit, required materials, estimated teacher preparation time, main concepts covered, activity descriptions and time to complete each, a troubleshooting list, and a list of additional resources.

- Lesson Plans - An overview of each individual activity, followed by detailed concept explanations, step-by-step instructions, and expected outcomes. The lesson plans also include additional explanation and discussion questions.

- Handouts - All handouts required for the activity are included: instructions, scientific method worksheets, and take-home activity information.

- Assessment - Each kit has pre- and post-activity questions for the students to complete.

Academic Activity: The first activity performed is an academic activity that helps students start thinking about the energy source, certain key concepts, and key terms. These activities are hands-on, but fairly brief.

Main Activity: The main activity is generally the most hands-on and time-intensive activity. Students can apply concepts from academic activities to the main activity. These activities involved the most design, analysis and construction by the TEAK team. Examples of the main 
activities are building an insulated model house (Heat Transfer) and simulating a hydroelectric facility by directing water through different paths to run a turbine (Wind and Water).

Take Home Activity: The intention of the take home activity is to have students relate what they learned from lessons and activities performed in the classroom to familiar real-world applications. Examples of take home activities include: reviewing their home heating bills with their parents and discussing what causes increased heating costs (Heat Transfer); evaluating data on the fuel consumption of various vehicles and brainstorming ways fuel efficiencies can be improved (Chemical); and thinking about power sources of everyday electronics such as an $\mathrm{iPod}^{\circledR}$ and evaluating whether solar energy can be used to supply power (Solar).

\section{Kit Descriptions}

The Chemical Energy Kit contains activities for the students to gain a better understanding about chemical energy, its use in creating mechanical, electrical, thermal, and light energy, how chemical energy is used in a diesel/internal-combustion engine to create mechanical work, and current research into alternative fuel sources. Basic concepts of chemical energy including transfer of electrons between two substances, oxidation, combustion, heat and light will be presented.

- In the first Academic Activity, students build $\mathrm{H}_{2}, \mathrm{O}_{2}, \mathrm{H}_{2} \mathrm{O}, \mathrm{NH}_{3}, \mathrm{CO}_{2}, \mathrm{CH}_{4}$, and $\mathrm{C}_{8} \mathrm{H}_{18}$, to learn about bonding and electron sharing. Students also evaluate environmental concerns associated with using different types of vehicles in their take home activity.

- In the second Academic Activity, creation of a fruit battery, students see how chemical energy can be harnessed from surprising sources. The fruit will light an LED that requires $\sim 2.5$ volts, and a current of $\sim 20 \mathrm{~mA}$. A single piece of fruit with a single zinc nail and a single copper nail will not light the LED, as it provides only an average of 0.54 volts. Students must demonstrate an understanding of power sources linked in series to successfully light their LED.

- In the Main Activity, students use a small fuel cell car to see the physical manifestation of what happens when water molecules are broken apart or formed; this ties into the first Academic Activity. The fuel cell car was chosen because it relates fundamental concepts of molecular bonding to chemical energy and shows how these molecules can create electricity that can then be used to power a car in a more environmentally friendly manner.

The Electrical Energy Kit introduces students to fundamental concepts related to storing and distributing energy. Students will construct simple circuits and analyze the electric potential of the designs they create. Concepts that are covered include Bohr's model of the atom, the concepts of charged particles, the ability of some circuit elements to store charge, and power consumption in a circuit and in physical devices.

- In the Academic Activity, students learn terminology related to electronics and discuss concepts such as closed vs. open circuits, resistance, and capacitance. These terms are important for completion of the Main Activities.

- In the Main Activity, students construct two circuits, each with a battery pack powering three light bulbs. One circuit has the bulbs in parallel and the other has bulbs in series. The students use multimeters to measure the current and voltage across each light bulb and discuss 
how this relates to the way power is distributed to individual homes in the community. If this is completed the students can additionally charge a capacitor, timing how long it takes the capacitor to discharge across an LED. The students use three different sized capacitors and compare discharge times, then discuss how this relates to the way energy is stored before use.

- In the Take Home Activity, students compare the cost to operate different electrical devices with different levels of power consumption.

The Heat Transfer Kit (Figure 1) lets students learn about the transfer of energy in the form of heat. The supporting activities were developed in direct support of the New York State Intermediate Science Education guidelines ${ }^{9}$. Middle school students learn that heat is based on three things: the temperature of the material, the mass of the material, and the material's composition. They also learn that heat moves from warmer to colder objects and can be transferred by conduction, convection, and radiation.

- In the Academic Activity, students see the difference between heat and temperature, and the different modes of heat transfer. They feel and measure the temperature of different sized balls made from different materials held in a constant temperature warm water bath, then use thermal crystals to visualize the rate of temperature change during conduction (touching with their hands) and convection (exposed to air).

- In the Main Activity, students build a small house using different types of insulation. The house is a cube with a floor, ceiling, and four walls made of four different materials: potting soil, fiberglass insulation, aluminum, and wood. The interior of the house is heated with a light bulb, and students calculate the rate of heat transfer through each of the four materials by taking temperature measurements and using the 1-D heat transfer equation. The materials were chosen because each represents a common building material and has a different thermal conductivity.

- In the Take Home Activity, students are asked to review their old home heating bills and think about the reasons for differences in the bills over the course of the year. They also look through their home for sources of heat loss and make suggestions about how to improve the insulation.

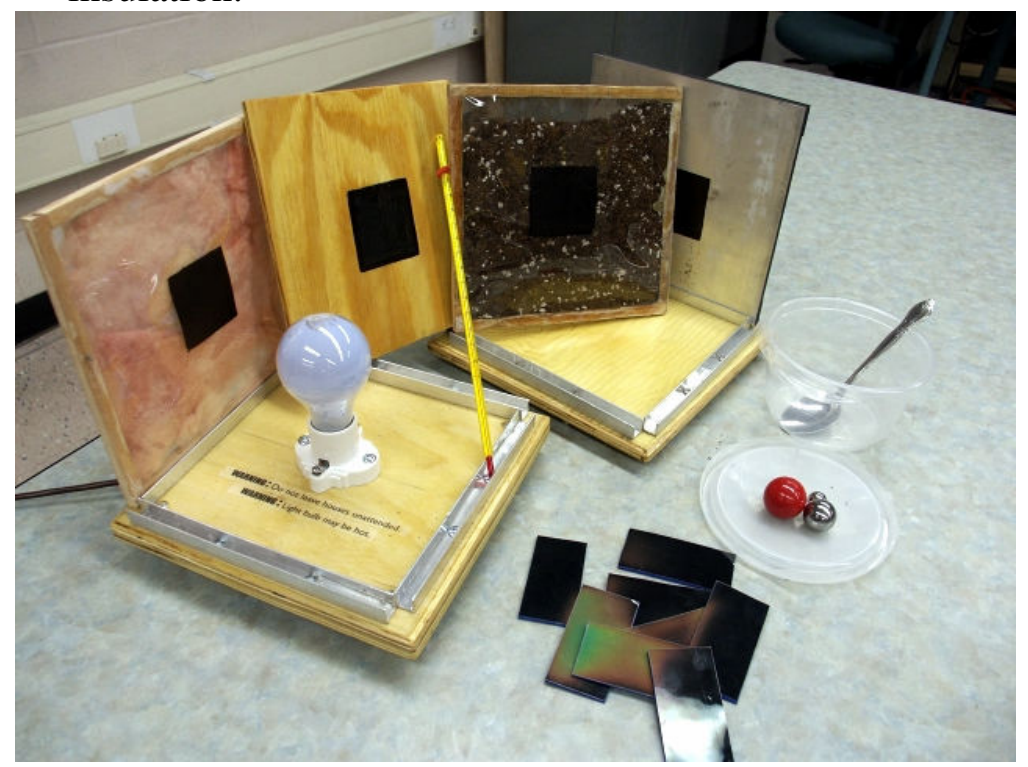

Figure 1. Heat Transfer Kit components. 
The Solar Power Kit teaches students about the ways in which solar power can be harnessed and introduces the concept of the energy cycle. Students learn about renewable, nonpolluting energy sources and some of the challenges that go along with collecting this energy.

- In the Academic Activities, students learn about the solar cycle, the different sources communities use to get their electricity, and how renewable resources like solar power can be used to provide electricity. Students also use a solar oven to cook a frozen pizza, and discuss ways in which solar power can be used for water and home heating and not just generating electricity. Based on tests the team conducted, the oven could reach $285^{\circ} \mathrm{F}$ at an insolation of $1020 \mathrm{~W} / \mathrm{m}^{2}$, which would be typical of a sunny day in Rochester, NY.

- In the Main Activity, students are provided with a small photovoltaic cell with an attached, regulated LED display and asked to go outdoors and gather solar energy themselves. The LED display segments the varying voltages from the photovoltaic cell, showing variation between brightly sunlit areas, cloudy areas, shady areas, and an indoor setting. As the amount of direct solar energy to the photovoltaic cells increases, the more lights on the bar graph will light up; this then shows what conditions are best for using photovoltaic cells to provide electricity.

- In the Take Home Activity, students look for products they use every day that can be powered by solar energy.

The Wind and Water Power Kit (Figure 2) also teaches students about renewable and nonrenewable energy sources, as well as how turbines work.

- In the Academic Activity, students look at different sources of energy and discuss which are renewable and which are nonrenewable, as well as why they place each source into its category. Students also use a small hand-powered generator that lights a bulb to see how mechanical energy can be converted to electricity.

- In the first Main Activity (2 parts), students enter into two competitions. First, they compete to see who can design the most efficient windmill, tying in with the Academic generator activity. Each team is given a hub that threads onto a rod. Teams place blades onto their hubs, and decide how many blades to attach to the hub, and at what angle the blades should be placed. Using a hair dryer to simulate a source of wind, teams test to see whose design moves the hub up the threaded rod the fastest. Next, the students control the flow of water through a system of pipes and valves to power a turbine. The turbine generates electricity, read digitally from a voltmeter. Student teams adjust the flow of water through the pipes by adjusting different valves, and they compete to see who can generate the most electricity.

- In the Take Home Activity, students are asked to look around their homes or places they visit to find sites that might be good candidates for wind- or water-based power plants. 


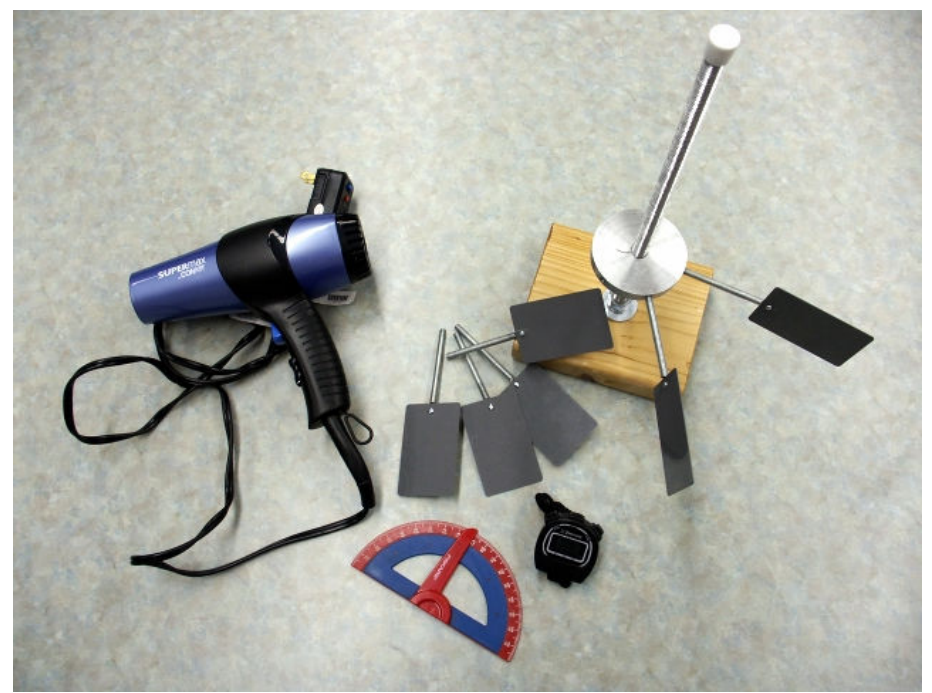

Figure 2. Wind and Water Power Kit components.

\section{TEAK Project Assessment}

Achievement of Objectives 1 and 2 for the project are being measured using pre- and postinstruction surveys. To date, over 100 students have completed these surveys for the various activities and the results are favorable. Objective 1, increase interest in engineering, is clearly being met, as 91/102 respondents have reported an increased interest in engineering after working through a TEAK activity. Objective 2 requires that students learn some basic engineering concepts; this has been harder to quantify, since some students have been able to correctly answer engineering-related questions prior to participating in the activities. As a whole, some subset of the students have shown an increase in knowledge after participating in each activity, from a low of 5/17 students showing improvement to a high of 17/28. Objectives 3 and 4 relate more to the design of the kits. Each kit's activities were developed to include design, not just science (Objective 3), and the kits are portable enough to be brought out into local schools rather than being restricted to on-campus use (Objective 4). As a whole, this indicates that all of our objectives are being met, with some room for improvement. Finally, the design team observed that middle school students got more out of presentations done on the RIT campus than when RIT students visited schools.

Feedback from instructors who have used the kits during the 2006-07 academic year to date is not complete yet. One instructor has filled out the post-kit survey and indicated that he was satisfied with the Electrical kit and plans to use other kits in the future. Two other instructors are also using kits - one with the help of an RIT student and one without - and have not returned surveys, but both have now requested all kits for their classes, to be used through the month of February. This has been interpreted as clear customer satisfaction.

The idea of working with MSD teams to design educational activities is a new one at RIT, and feedback and observations from students and faculty involved with the project will be helpful in future work with new teams. Responses from the MSD team developing the TEAK hardware were as follows:

- It was clear that the TEAK project serves a valuable purpose in educating future engineers. 
- The project gave the team an appreciation of engineering and community issues related to energy and the environment.

- It would have been helpful to have included team members or consultants who had a background in education.

- The project provided an opportunity to learn about the design process and how to work closely with people from different disciplines.

- There was mixed feedback on the type of project. Most team members indicated that the TEAK project was more meaningful than a typical MSD project, both because it helps to further STEM education and because the kits continue to be in demand from local educators. One student indicated that the TEAK project did not seem appropriate for MSD because of the perceived lack of technical content and because the project requirements were so different from the typical MSD project.

Faculty observations include:

- The team put a great deal of effort into developing the kits' supporting documentation. While this has effort been greatly appreciated by teachers using the kits now, it would have been helpful to have included team members or consultants who had a background in education.

- There was a perception on the part of some team members and other faculty that this was a non-technical project.

- The project should have included some specific requirements that would have reinforced the engineering content of the project, particularly (1) additional testing to ensure that the final hardware would be durable enough to withstand transportation and repeated use by precollege students and (2) additional analysis to reduce the amount of time spent on trial-anderror design work.

\section{Future Plans - Improving and Expanding TEAK}

While the current TEAK project has been very successful in bringing engineering activities and ideas for careers in engineering to elementary and middle school students, continuous improvements are necessary. First and foremost, during transportation and extensive use during the past year, it has become clear that some of the TEAK components will need frequent repair or replacement. Some hardware may need to be modified to be more robust, and a fee structure for kit rental will be established to cover the costs of parts and labor associated with kit maintenance. To allow future design teams to focus more on designing hardware that can withstand heavy use, future TEAK projects will involve closer partnerships with education experts to support development of the lesson plans. Finally, some classes have taken longer than anticipated with the engineering activities and run out of time to complete the post-project assessments. Since this information is critical to content improvement, the time allocations for some activities need to be re-evaluated so that teachers can budget appropriate time to complete all assessments.

While the part-time engineering student workers and the MSD team have done a good job developing and piloting the kits, a key element of the TEAK future plan involves creation of one or two co-op positions for full-time student work. These students would have the opportunity to help design and build new kit hardware, maintain existing kit hardware, create new activities and 
lesson plans, and teach engineering to pre-college students. Ideally, kit rental fees will be sufficient to pay for these student hires.

\section{Acknowledgement}

The authors would like to acknowledge the American Society of Heating Refrigeration and AirConditioning Engineers for support under their Senior Projects Grant and the American Society of Mechanical Engineers for support under their Diversity Action Grant.

References

1. National Science Board. 2006. Science and Engineering Indicators 2006. Two volumes. Arlington, VA: National Science Foundation (volume 1, NSB 06-01; volume 2, NSB 06-01A).

2. National Science Foundation, Division of Science Resources Statistics, Women, Minorities, and Persons with Disabilities in Science and Engineering: 2004, NSF 04-317 (Arlington, VA, 2004).

3. Profiles of Engineering and Engineering Technology Colleges, 2005 Edition, American Society for Engineering Education.

4. Senay Yasar, Dale Baker, Sharon Robinson-Kurpius, Stephen Krause, and Chell Roberts, "Development of a Survey to Assess K-12 Teachers' Perceptions of Engineers and Familiarity with Teaching Design, Engineering, and Technology", Journal of Engineering Education, v. 95, pp. 205-216 (2006).

5. "Cool Science Kit", American Society of Heating, Refrigeration, and Air-Conditioning Engineers, http://www.ashrae.org/publications/detail/15029

6. Pamela Cantrell, Gokhan Pekcan, Ahmad Itani, and Norma Velasquez-Bryant, "The Effects of Engineering Modules on Student Learning in Middle School Science Classrooms", Journal of Engineering Education, v. 95, pp. 301-309 (2006).

7. "Bloom's Taxonomy" http://www.kent.k12.wa.us/ksd/MA/resources/blooms/blooms.html

8. A. McKenna and A. Agogino, "A Web-Based Instructional Module for Teaching Middle School Students Engineering Design with Simple Machines”, Journal of Engineering Education, v. 87, pp. 437-444 (1998).

9. "Intermediate Level Science Core Curriculum Grades 5-8". The University of the State of New York. http://www.emsc.nysed.gov/ciai/mst/pub/intersci.pdf 